Revista Monografias Ambientais - REMOA v. 14, 2015, p. 107-120

\title{
Interdisciplinaridade e transversalidade na geografia: uma estratégia de ensino-aprendizagem
}

Interdisciplinary approach and transversal themes uses in geography: a learning strategy

\author{
Jucemeire Borges Soares da Silva ${ }^{1}$, Luciana Borba Benetti ${ }^{2}$
}

${ }^{1}$ Pós-Graduanda do Curso de Especialização em Educação: Interdisciplinaridade e Transversalidade, Universidade Federal do Pampa, São Gabriel, RS, Brasil.

${ }^{2}$ Doutora em Engenharia Ambiental, Docente na Universidade Federal do Pampa/São Gabriel, RS, Brasil.

\begin{abstract}
Resumo
A interdisciplinaridade propõe a troca de reciprocidade e intensidade entre as disciplinas tornando possível aos alunos uma compreensão mais completa de uma situação problema, ultrapassando a fragmentação do conhecimento. O presente artigo versa sobre uma estratégia interdisciplinar, envolvendo o tema transversal: Meio Ambiente, na disciplina de Geografia, a qual foi aplicada na Escola Estadual de Ensino Fundamental Dr. Pery da Cunha Gonçalves, localizada no município de São Gabriel/RS, no $6^{0}$ ano, turma $A$, do Ensino Fundamental. Foram abordados temas como: separação do lixo, coleta seletiva, reciclagem, poluição, uso consciente da água. A metodologia desenvolvida foi a partir da prática de projetos temáticos, que proporcionaram uma compreensão da multiplicidade de aspectos que compõem a realidade, uma vez que permite a articulação de contribuições de diversos campos de conhecimento. Um dos resultados importantes deste trabalho foi o de despertar nos educandos uma consciência ambiental e promover uma aprendizagem mais significativa, o que ficou evidenciado nos resultados das avaliações em comparação aos resultados da turma onde não foi aplicada a estratégia interdisciplinar.
\end{abstract}

Palavras-chave: Interdisciplinaridade, Meio Ambiente, Geografia, projetos temáticos.

\begin{abstract}
Interdisciplinary approach means exchanging reciprocity and intensity among different school subjects allowing students to get a wider comprehension and understanding of situations and problems, overcoming the fragmentation of the knowledge. This article deals with the transversal theme Environment in the subject of Geography, which was developed at Escola Estadual de Ensino Fundamental Dr Pery da Cunha Gonçalves, located in São Gabriell RS, 6o grade, class A. The following themes were studied: garbage separation, selective collection of the garbage, pollution, reasonable use of water. The methodology used was doing projects to help students understand all the multiple aspects of their reality, showing them that a sustainable approach is possible and this way the learning process becomes more significant as it was demonstrated by the evaluation process results that were compared to the group which was not part of the research.
\end{abstract}

Key words: interdisciplinary approach, Environment, Geography, theme projects. 
No mundo atual, faz-se necessária uma proposta educacional adequada às necessidades sociais, políticas, econômicas e culturais da realidade, que considere os interesses dos alunos e garanta as aprendizagens essenciais para a formação de cidadãos autônomos, críticos, participativos, capazes de atuar com competência, dignidade e responsabilidade na sociedade em que vivem. A educação é elemento indispensável para a formação da consciência ambiental e a escola tem o importante papel de informar a nova geração sobre a gravidade dos problemas ambientais e incentivar os alunos na busca de soluções. A escola é o espaço essencial para o desenvolvimento do conhecimento partilhado e para a integração com a comunidade. Nela encontra-se grande parte da população que demonstra interesse em aprender, e onde reside o grande potencial disseminador de informações que ultrapassam, por inúmeras vezes, seus limites físicos (OLIVEIRA, BUENO, 1997). A escola é um dos alicerces da educação, da cidadania e da formação de uma nação. É, por meio dela, que uma criança inicia sua educação, sua integração e inclusão social, seus relacionamentos e seus potenciais, ou seja, relações complexas que se estendem por toda a vida. É no ambiente escolar que a criança passa a observar questões relativas ao meio ambiente, à saúde e também ao próprio cuidado com o corpo, tratando-se de um local de intensas descobertas. Nesse ambiente ideal a criança explora suas potencialidades e vive inúmeras descobertas.

Partindo disso, a proposta do projeto é trabalhar com a construção de conhecimento significativo, no qual o aluno é sujeito de seu aprendizado. Por meio de projetos interdisciplinares o aluno torna-se mais crítico e criativo numa perspectiva de formação plena. Nesse contexto, o papel do professor é de fundamental importância para o desenvolvimento da prática interdisciplinar, superando velhos hábitos e refletindo sobre novas práticas educativas, buscando parcerias, sempre que possível, com colegas que atuam em diferentes campos do conhecimento que compõem o currículo escolar.

O trabalho com projetos possibilita também a percepção global da realidade de forma dinâmica e interdisciplinar atendendo à evolução do pensamento infantil. Algumas teorias sobre o processo de aprendizagem da criança apontam para o fato de que ela percebe o objeto em sua totalidade e não de forma fragmentada. À medida que seu pensamento evolui, a criança torna-se cada vez mais capaz de perceber as partes que compõem o todo e de estabelecer relação entre elas, recompondo-as na sua totalidade.

Segundo Leite,

“[...] a Pedagogia de Projetos se coloca como uma das expressões dessa concepção globalizante que permite aos alunos analisar os problemas, as situações e os acontecimentos dentro de um contexto e em sua globalidade, utilizando, para isso, os conhecimentos presentes nas disciplinas e sua experiência sociocultural." (1996, p. 29)

Segundo Fazenda (1996), interdisciplinaridade é uma atitude, isto é, uma externação de uma visão de mundo que, no caso, é holística. O terno holístico, do grego holos = totalidade; refere-se a uma compreensão da realidade em função de totalidades integradas cujas propriedades não podem ser reduzidas a unidades menores.

Morin (2002), reconhecido como um pensador contemporâneo transdisciplinar, defende a interligação das várias áreas para construção do conhecimento, combate o reducionismo, valoriza o complexo. Segundo ele, sala de aula é um fenômeno complexo, um espaço heterogêneo, com 
diversidades de experiências, ânimos, culturas, classes sociais e econômicas, sentimentos, etc. Considerando o currículo escolar mínimo e fragmentado, sem proporcionar uma visão holística. As disciplinas quando não se integram dificultam a perspectiva global que favorece a aprendizagem. Outro ponto importante na obra de Morin trata da contextualização, da necessidade de inserir partes no todo, uma vez que, informações dispersas, que não se inserem na visão geral de mundo e não têm ligações com redes cognitivas pré-existentes em cada pessoa, deixam de ser significantes.

Japiassu (1976) trata o fenômeno interdisciplinar como uma nova maneira de encarar a repartição epistemológica do saber em disciplinas e das relações entre elas, pois se trata de uma das mais significativas mudanças que afetam, em nossa cultura, as démarches da inteligência e as formas de seu discurso. Faz uma Reflexão sobre as condições reais em que se produzem, se elaboram e se articulam os conhecimentos interdisciplinares, com vistas ao estabelecimento de uma convergência para o entendimento e a compreensão de um fenômeno.

Segundo Auler (2007, p.7), “a interdisciplinaridade requer a análise sob vários olhares disciplinares articulados em torno de um tema constituído de um problema aberto, sendo os problemas ambientais representantes típicos." Logo, quando se trata do meio ambiente, a interdisciplinaridade aparece como palavra de ordem nas propostas pedagógicas (FAZENDA, 2011). O meio ambiente é um tema frequente no currículo escolar. Porém por se tratar de um tema amplo, os Parâmetros Curriculares Nacionais ( $\mathrm{PCN}$ ) o consideram como tema transversal, possibilitando sua abordagem em diferentes disciplinas, nos diferentes níveis de ensino. De acordo com os PCN,

“[...] a transversalidade diz respeito à possibilidade de se estabelecer, na prática educativa, uma relação entre aprender conhecimentos teoricamente sistematizados (aprender sobre a realidade)e as questões da vida real e de sua transformação (aprender na realidade e da realidade). É uma forma de sistematizar esse trabalho e incluí-lo explícita e estruturalmente na organização curricular, garantindo sua continuidade e aprofundamento ao longo da escolaridade. “(BRASIL, 1998, p. 30)

Segundo os PCNs, os temas transversais configuram-se como processos vividos intensamente na sociedade e que no currículo escolar aparecem de forma implícita ou explícita em diversos momentos, porém sua complexidade não permite que sejam trabalhados separadamente.

Esta consideração remete ao presente artigo que faz um estudo sobre o tema EA (Educação Ambiental) inserida no processo de ensino-aprendizagem. $O$ trabalho voltado ao ensino, que discuta a temática ambiental, merece atenção especial considerando os grandes problemas vivenciados na atualidade como enchentes, efeito estufa, mudanças climáticas, desmoronamentos, escassez de água potável, produção de lixo, secas, entre outros. Considerando a urgência dessas questões ambientais, é importante que existam propostas educativas, como aulas e projetos interdisciplinares, que possam promover uma compreensão crítica da realidade, por parte dos alunos, das transformações negativas que o meio ambiente vem sofrendo, para que estes possam adquirir uma consciência ambiental e que passem adiante seus conhecimentos com práticas concretas de preservação ambiental. 


\section{Caminhos metodológicos}

O trabalho realizado baseia-se em um estudo de caso sobre práticas pedagógicas direcionadas aos alunos como forma de promover uma aprendizagem mais prazerosa e significativa, resgatando um espaço que o desafie a raciocinar, argumentar, negociar e refletir, habilidades que são bastante demandantes do ponto de vista cognitivo e social.

Este estudo de caso está ligado a uma pesquisa exploratória diante de um problema considerável de um determinado grupo que, segundo Gil (1991), é um estímulo para novas descobertas e por ser um planejamento flexível "o pesquisador, ao longo de seu processo, mantém-se atento a novas descobertas".

O principal objeto de estudo é a prática pedagógica desenvolvida no $6^{\circ}$ ano, turma $\mathrm{A}$, do Ensino Fundamental da Escola Estadual de Ensino Fundamental Dr. Pery da Cunha Gonçalves, no município de São Gabriel, Rio Grande do Sul, durante o primeiro trimestre de 2015, contemplando 27 alunos.

A metodologia do trabalho está dentro de uma abordagem investigativa, visando criar maior familiaridade em relação à realidade da comunidade escolar inserida no projeto.

O primeiro passo foi decidir qual o tema seria trabalhado, de maneira interdisciplinar, que relacionasse os conteúdos das disciplinas de Geografia, Artes, Português e Ciências. Foi escolhida a Educação Ambiental, considerando a importância da temática ambiental, dentro do tema transversal meio ambiente. Com isso, o trabalho propõe a interdisciplinaridade como estratégia de ensinoaprendizagem, usando como ferramenta a Educação Ambiental. A partir do momento da inserção de uma proposta pedagógica diferenciada, será avaliado o interesse e o rendimento dos alunos na disciplina de Geografia, nas avaliações dos conteúdos previstos para o primeiro trimestre, bem como, a mudança de atitudes que adotarão para transformar a realidade em que vivem, conscientes do seu papel no mundo.

Após esse processo foram traçados os objetivos a serem alcançados com o projeto interdisciplinar e quais os tópicos seriam importantes para uma reflexão crítica sobre os problemas da sociedade, despertando nos alunos um sentimento de cidadania.

Com base nesse quadro, as ações desenvolvidas estão diretamente ligadas ao contexto social, criando assim, um espaço coletivo centrado em um objetivo: Desenvolver atividades de Educação Ambiental, nas aulas de Geografia, oferecendo meios efetivos para que cada aluno compreenda os fatos naturais e humanos a respeito do meio ambiente, desenvolvendo suas potencialidades e adotando posturas pessoais e comportamentos sociais, diante da ação pedagógica que envolve a Educação Ambiental, que lhes permita viver uma relação construtiva consigo mesmo e com o seu meio.

As ações foram construídas e adaptadas buscando desenvolver intervenções interdisciplinares que possibilitassem a educação integral dos indivíduos de acordo com as propostas do projeto, de forma participativa e cooperativa, envolvendo os alunos e professores através de oficinas, entrevistas, saída de campo, vídeos de sensibilização, sequência didática, textos informativos, palestras e observações em diário de acompanhamento como forma de aproximação do significado que a Educação Ambiental possui aos sujeitos envolvidos. A participação ativa dos alunos em pesquisas e produções de referenciais ao longo do projeto será em forma de registro que todos possam compartilhar, e, assim, conheçam e discutam a produção uns dos outros.

Com isto, pretende-se: 
- Compreender o processo de ensino-aprendizagem a partir de práticas pedagógicas relacionadas à questão ambiental com vistas à construção da consciência crítica acerca da relação ser humano e natureza.

- Perceber que somos interdependentes da natureza e as relações de causa e efeito condiciona a vida no espaço e no tempo.

- Conhecer e compreender, de modo integrado e sistêmico, as noções básicas relacionadas ao consumo responsável, energia, água e lixo.

- Adotar posturas que levem às interações construtivas, justas e ambientalmente sustentáveis.

- Observar e analisar fatos e situações do ponto de vista ambiental, de modo crítico, reconhecendo a necessidade e as oportunidades de atuar de modo reativo para garantir um meio ambiente saudável e a boa qualidade de vida.

- Perceber, apreciar e valorizar a diversidade natural e sócio-cultural, adotando posturas de respeito aos diferentes aspectos e formas de patrimônio natural, étnico e cultural.

- Avaliar o processo de ensino-aprendizagem com vistas à construção de conceitos que possam interferir no cotidiano do educando.

- Enriquecer o currículo do educando.

Com base no problema e nos objetivos estruturados para o desenvolvimento, a metodologia empregada terá como base a pesquisa-ação, pois esta assume características essenciais para desenvolver trabalhos dentro da realidade social como a identificação e interpretação das dificuldades/problemas em que a prática educativa ou, até mesmo, a situação social se encontra. Ela se apresenta como forma alternativa de pesquisa, onde o pesquisador e o pesquisado se envolvem no processo. Pode ser usada como instrumento de transformação social, interagindo de forma coletiva, baseada no diálogo que gera a reflexão para posterior ação.

A pesquisa-ação provoca uma mobilização dos agentes transformadores (educandos) a partir de uma reflexão sobre o problema detectado e um resgate para posterior planejamento e ação a ser desenvolvida. Além disso, proporciona aos educandos a formulação hipóteses, a organização de suas ideias, a coleta, a interpretação e avaliação de evidências, chegando assim a conclusões que podem levar a um agir dentro do seu meio, partindo do individual para o coletivo.

Esta concepção metodológica permite aos sujeitos o aprofundamento da sua compreensão da situação vivida, a elaboração coletiva de estratégias para solucionar os problemas diagnosticados e a construção de novos conhecimentos através do diálogo.

\section{$3 \quad$ Percorrendo caminhos}

As atividades tiveram início com um levantamento dos conhecimentos prévios dos alunos sobre Educação Ambiental, mais especificamente meio ambiente, resíduos sólidos, coleta seletiva, água, energia e consumo. O projeto foi desenvolvido em horário extraclasse e as aulas de Geografia ministradas dentro da carga horária prevista, sendo desenvolvidos os conteúdos programados normalmente.

O projeto foi conduzido de acordo com as seguintes etapas: 


\title{
ETAPA 1: Textos informativos
}

A busca de informações em diferentes fontes constitui uma das características do trabalho por meio de projetos. O uso de textos informativos, embora seja uma estratégia muito aplicada em sala de aula, nem sempre é bem explorada pelos professores, que muitas vezes trabalham apenas com perguntas e respostas, que traduzem o texto, desconsiderando a sua compreensão. Uma dificuldade apresentada pelos alunos refere-se à leitura e à compreensão dos textos. Entende-se por compreensão do texto, um processo interativo que implica a construção de sentido, ou seja, ao ler um texto, o aluno aprende seu significado e estabelece conexões que podem contribuir para reavaliar suas idéias a respeito do assunto.

Partindo deste pressuposto, os PCNs colocam que:

\begin{abstract}
"Além do livro didático, outras fontes oferecem textos informativos: enciclopédias, livros paradidáticos, artigos de jornais e revistas, folhetos de campanhas de saúde, de museus, texto de mídia informatizada de textos informativos, etc. É importante que o aluno possa ter acesso a uma diversidade de textos informativos, pois cada um deles tem estrutura e finalidades próprias. Os textos trazem informações diferentes e muitas vezes divergentes sobre o mesmo assunto, além de requererem domínio de diferentes habilidades e conceitos para sua leitura." (BRASIL, 1997. v. 4, p. $81)$.
\end{abstract}

Partindo desses princípios foram oferecidos diferentes textos selecionados previamente, como: reportagens locais sobre a coleta seletiva implantada recentemente na nossa cidade, informativos sobre resíduos sólidos, as cores internacionais da reciclagem do lixo, noção da quantidade de resíduos que são produzidos durante o dia em nossa casa, na cidade, no mundo, poluição das águas. De posse dos textos, os alunos realizaram a leitura, discutiram as ideias, colheram dados importantes, como por exemplo, a cor das lixeiras para a separação do lixo, o tempo de decomposição de diversos objetos quando jogados na natureza. No grande grupo, foram expostas as conclusões e um debate sobre o que cada um tem feito para contribuir com a temática ambiental. Essa atividade proporcionou uma socialização e participação de todos. E finalizando a atividade, foi proposta a produção de um texto coletivo a partir das conclusões sobre a temática.

\section{ETAPA 2: Exibição de vídeos}

Para uma maior proximidade com a realidade, mobilizar os alunos para a temática ambiental e refletir sobre as relações homem-natureza, foram exibidos dois documentários: “Entre rios", disponível no youtube, "Você é vítima do seu lixo", produzido por acadêmicos do curso de Biologia da Universidade Federal do Pampa, campus de São Gabriel, e desenhos animados sobre educação ambiental. Com o objetivo de tornar a aula mais dinâmica e agradável, foi utilizado o recurso multimídia para a exibição de imagens obtidas em sites de pesquisa, como Google, assim como vídeos adquiridos através do youtube. $\mathrm{O}$ uso de recursos audiovisuais é excelente para o desenvolvimento de um projeto, usados de forma planejada e intencional, são fortes aliados no processo de ensinoaprendizagem.

Freitas (2007) faz uma análise dos recursos audiovisuais, segundo ele 
“[...] Eles facilitam a compreensão do mundo real, dos fenômenos naturais, pois podem apresentar fatos do presente e do passado, além de fazer previsões para o futuro. Aproximam locais distantes, levantam problemas, propõem soluções e trazem milhares de informações, podendo ainda, estimular a criatividade e trabalhar o imaginário." (FREITAS, p. 44)

De acordo com o que temos observado, cada vez mais cedo, os alunos já fazem uso de algum recurso tecnológico em vários espaços e contextos que não o da escola. A inclusão desses recursos no processo de ensino-aprendizagem contribui para a compreensão do dinamismo com que os conhecimentos são veiculados no mundo, auxiliando o aluno na construção de conhecimentos de forma mais atraente.

E para concluir essa etapa do projeto, os alunos produziram textos sobre os documentários e criaram uma história em quadrinhos sobre a Educação Ambiental.

\section{ETAPA 3: Saídas de campo}

Essas atividades foram planejadas para serem desenvolvidas fora da sala de aula, com fins investigativos e de aprendizagem. Ao observar o espaço ao seu redor, o seu bairro, a sua comunidade escolar, o aluno poderá analisar de forma mais crítica as interações e transformações realizadas pela ação humana e, através de suas investigações, construírem novos conhecimentos. Nessa etapa do trabalho, foi feito um passeio com a turma pelo bairro onde está localizada a escola, com o objetivo de identificar problemas ambientais na comunidade, como por exemplo, a poluição/contaminação da água e esgoto e avaliar a limpeza do bairro, a existência de lixeiras coletivas e individuais, condicionamento do lixo pelos moradores. Os alunos fotografaram todos os problemas identificados, assim como os bons exemplos encontrados. Foram observados muitos casos de desrespeito à natureza, como lixo espalhados por todos os lugares ( pneus, móveis e até roupas velhas atiradas em terrenos baldios), esgoto a céu aberto, reduzido número de lixeiras, a maioria das casas não separam o lixo seco do orgânico. Após esse trabalho de campo, foram projetados slides com as imagens das fotografias feitas pelos alunos, que iam comentando e discutindo cada problema ambiental identificados. 
Figura 1: Passeio pelo bairro Belo Vista, nas proximidades da E. E. E. F. Dr. Pery da Cunha Gonçalves, em São Gabriel/RS.

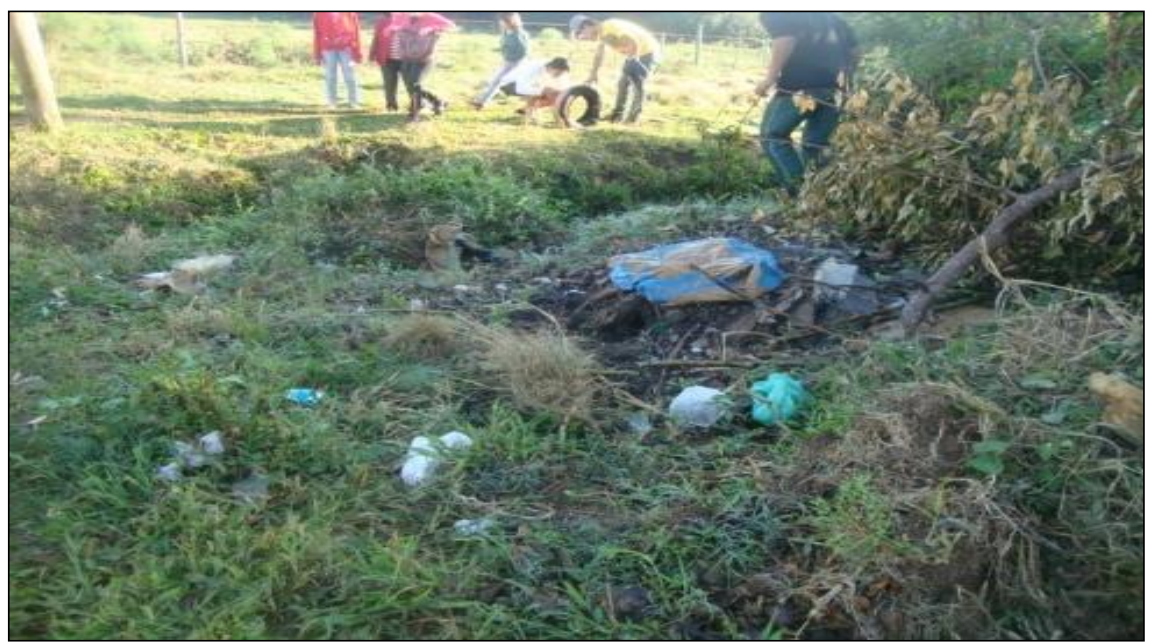

Fonte: Autores

Em um segundo momento, das saídas de campo, a turma visitou o centro de apoio ao catador, o projeto Minuano. Lá puderam conhecer todo o processo da separação e armazenamento do lixo seco, a rotina dos catadores, as dificuldades encontradas pelas famílias que dependem do lixo que produzimos e a importância da separação do lixo seco do orgânico em nossas casas para a saúde dessas pessoas. O que mais chamou a atenção nesse passeio foi a preocupação dos catadores com o meio ambiente.

Figura 2: Visita ao centro de apoio ao catador, Projeto Minuano, localizado no Bairro Vargas, em São Gabriel/RS.

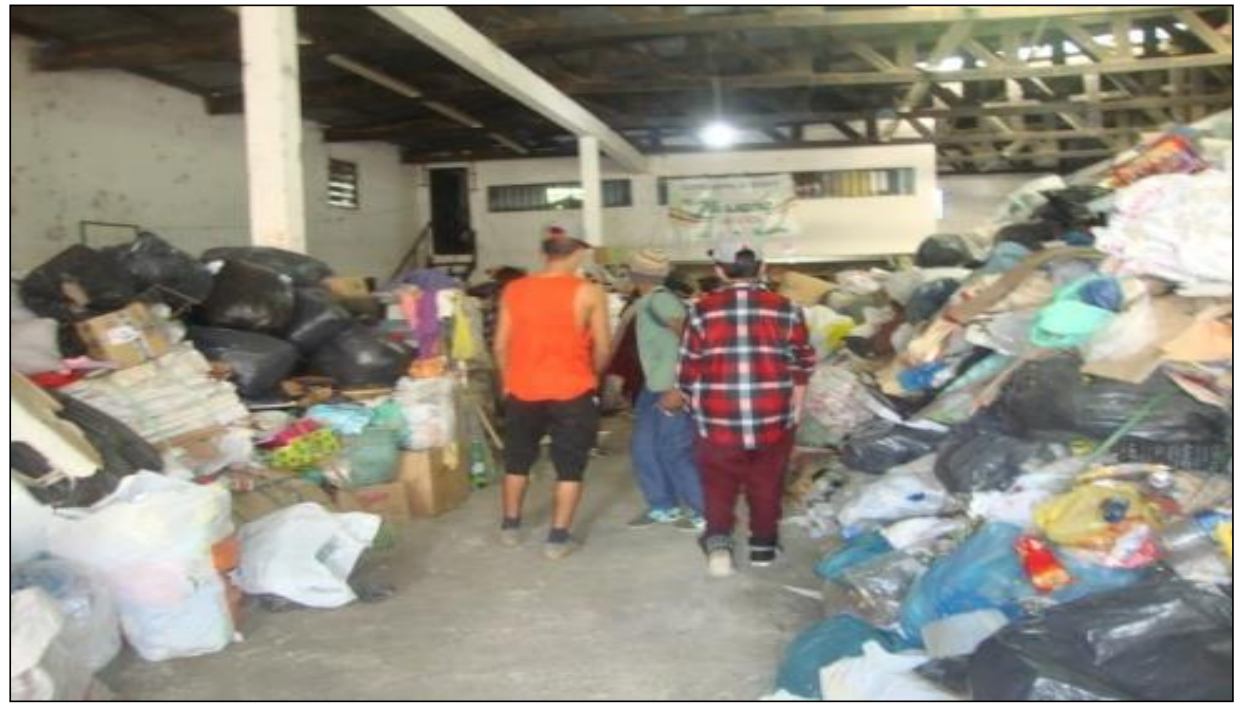

Fonte: Autores

\section{ETAPA 4: Palestras e entrevistas}

Essas estratégias constituem num instrumento interessante para recolher dados e possibilitar ao aluno maior proximidade com a realidade que o cerca. Nessa etapa foram proporcionadas duas palestras: a primeira sobre a água e esgoto da cidade, com técnicos da empresa de tratamento de água 
e esgoto de São Gabriel, da São Gabriel Saneamento, e a outra com a, sr ${ }^{\mathrm{a}}$ Maria Otília, presidente da associação dos catadores da cidade, que falou sobre o centro de apoio ao catador, denominado projeto Minuano, implantado recentemente na cidade. Foram realizadas entrevistas no final das palestras, com um roteiro de perguntas preestabelecidas pelos alunos com o auxílio do professor. Com a realização dessa atividade os alunos tiveram a oportunidade de conversar, discutir, comentar os conhecimentos e organizar uma síntese dos pontos importantes.

Figura 3: Palestra com os Técnicos da São Gabriel Saneamento, empresa responsável pelo tratamento de água e esgoto, realizado em uma sala de aula da E. E. E. F.. Dr. Pery da Cunha Gonçalves, em São Gabriel/RS.

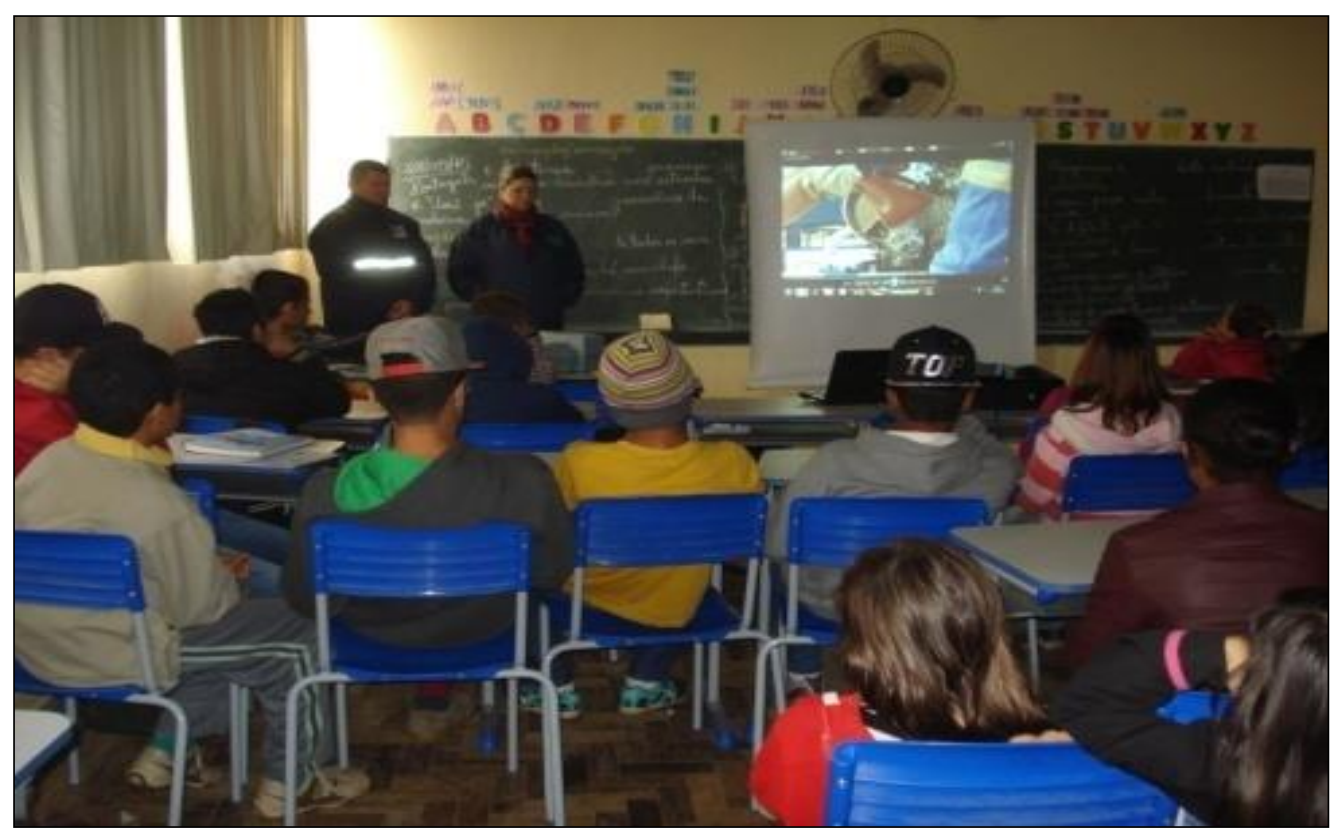

Fonte: Autores

Figura 4: Palestra com a presidente da Associação dos Catadores de São Gabriel, Sra Maria Otília, na sala de aula do 6⿳0 ano A da E. E. E. F.. Dr. Pery da Cunha Gonçalves, em São Gabriel/RS. 


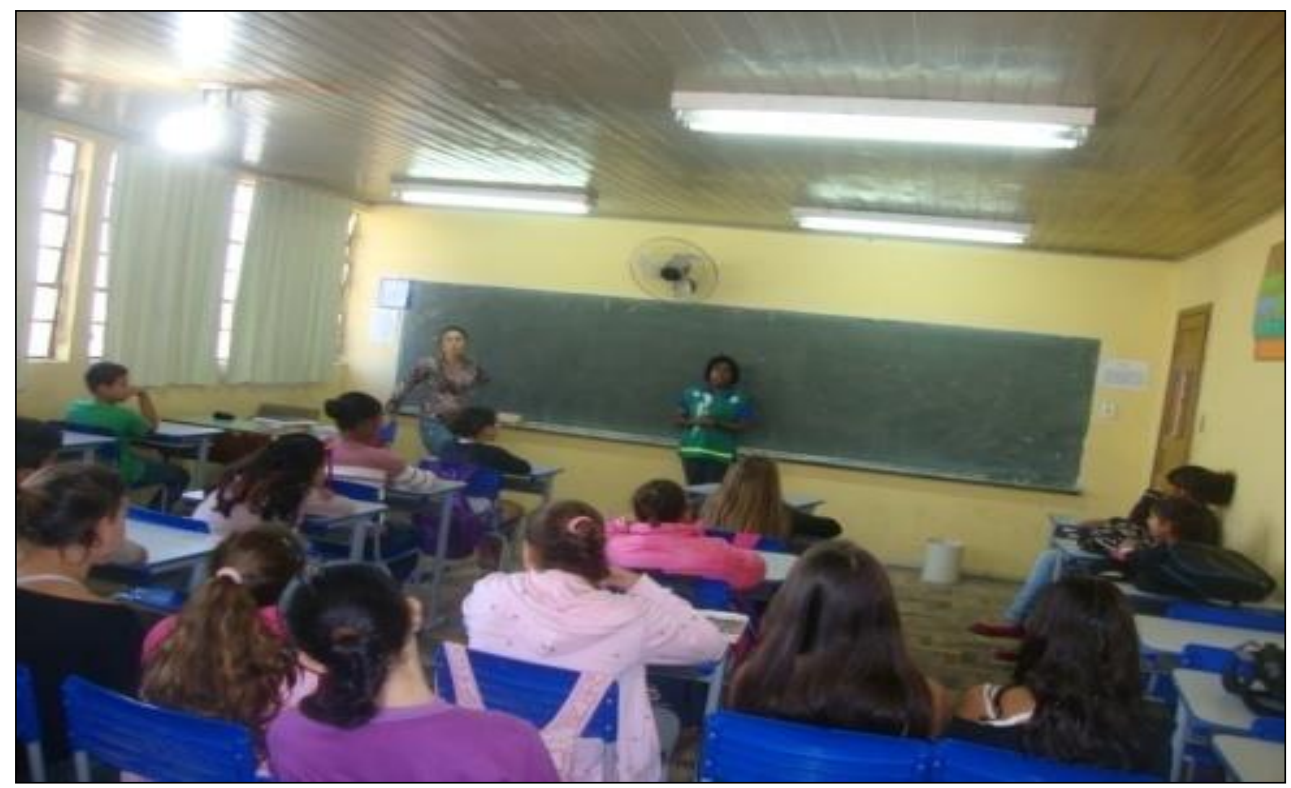

Fonte: Autores

\section{ETAPA 5: Campanha de Conscientização}

Esse foi o momento no qual os alunos puderam demonstrar os conhecimentos adquiridos durante o projeto, repassando-os a outros alunos, através de visitas nas salas de aula, distribuindo panfletos com dicas para economia de água, separação correta do lixo doméstico, dias da coleta seletiva no bairro. Realizaram também o monitoramento do recreio, orientando os demais alunos a cuidarem da limpeza da escola e a colocarem o lixo nas lixeiras corretas: seco e orgânico. Foram confeccionados coletes com o slogan da campanha: PEQUENAS AÇÕES, GRANDES IMPACTOS, usados pelos alunos e professores engajados no projeto. $\mathrm{O}$ fechamento desse trabalho foi uma caminhada pelo bairro, com a distribuição de panfletos e conversa com os moradores.

Figura 5: Campanha de Conscientização com panfletagem no bairro Bela Vista, nas proximidades da E. E. E. F. Dr. Pery da Cunha Gonçalves, em São Gabriel/RS.

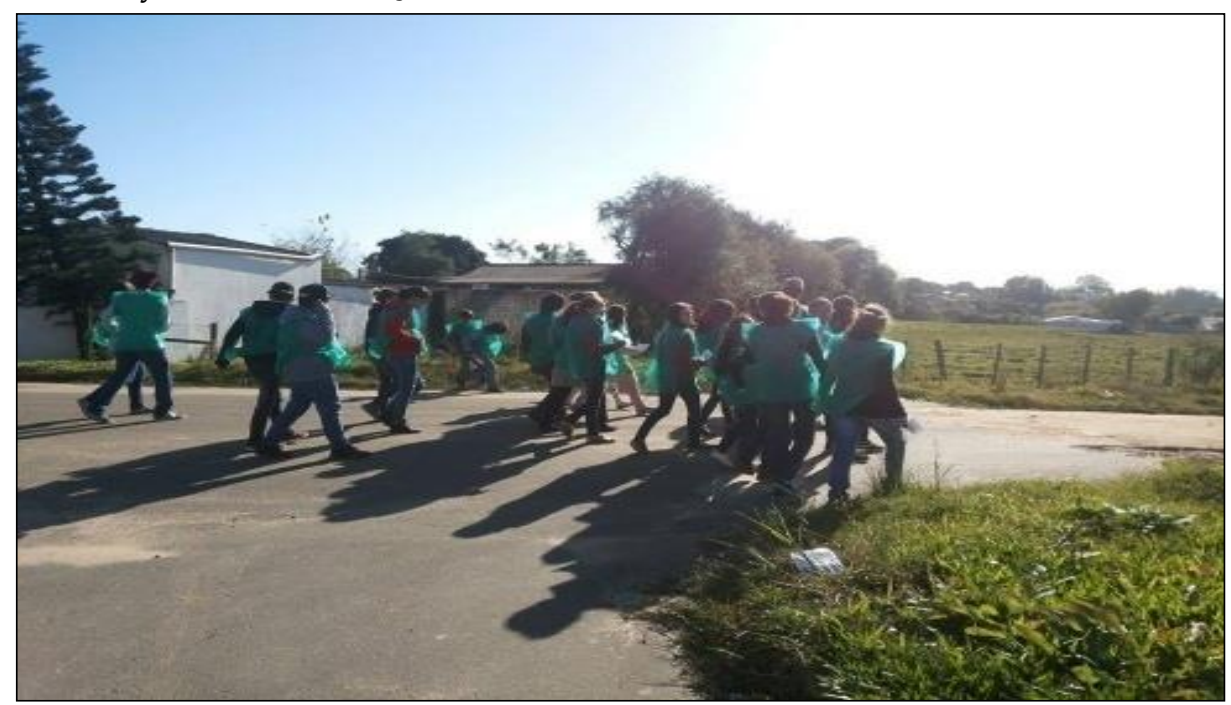

Fonte: Autores 


\section{Considerações Finais}

Diante dos caminhos percorridos nesse trabalho, pode-se salientar que hoje, mais do que nunca, professores e escolas devem incluir nos seus currículos temas ligados à crise ambiental, institucionalizando um espaço para que a EA seja trabalhada de forma inter e multidisciplinar, proporcionando condições para o debate crítico, apontando para a busca de soluções para os problemas ambientais. A Terra é um paciente doente e sua recuperação depende da mudança de postura e hábitos já cristalizados em nossa sociedade. A escola precisa informar a nova geração sobre a gravidade dos problemas ambientais e incentivar os alunos na busca de soluções.

Vários estudos mostram a importância da integração de conteúdos dos componentes curriculares para consolidar a interdisciplinaridade. Essa cooperação entre as disciplinas promove o aumento de interesse dos alunos, além de levar a uma melhor interpretação do assunto estudado, melhorando a aprendizagem. A interdisciplinaridade leva à contextualização e à articulação do conhecimento produzido e vivenciado pelo homem.

Esta mudança tão necessária no processo ensino-aprendizagem só se tornará realidade quando for tomada como uma atitude, um novo modo de pensar, fazendo parte da organização curricular, modificando as metodologias de ensino e se tornando parte da formação dos profissionais da educação. A interdisciplinaridade não é mais uma "moda", agora ela faz parte do contexto do ensino. Ser interdisciplinar é um estado, não um momento. A interdisciplinaridade não pode ser resumida em conversas na sala dos professores, com as atribulações do dia-a-dia, é preciso sistematizar reuniões para que essa prática se efetive. Esse foi o maior problema observado durante a realização desse trabalho, a falta de reuniões para o planejamento interdisciplinar.

Foi observado que o grande desafio da interdisciplinaridade é mudar o comportamento dos professores para que, sem conflitos, compartilhem seus conhecimentos. A cada dia, o mundo está cada vez mais interconectado e interdisciplinarizado e a escola, lugar onde se efetiva aprendizagem, precisa acompanhar estas mudanças que acontecem em toda sociedade, participando da construção de novos conhecimentos. Não é fácil trabalhar a interdisciplinaridade, é necessária uma mudança de costumes, ir buscar do novo, rompendo com os velhos hábitos e acomodações, enfrentando desafios. Entretanto, um dos entraves para essa prática é a falta de tempo disponível para o planejamento dentro da carga horária do professor.

Acredita-se que um processo educativo, através da interdisciplinaridade, possibilita compreender melhor a relação entre teoria e prática, levando a escola a formar pessoas mais críticas, criativas e responsáveis. O professor precisa tornar-se um profissional com visão integrada da realidade, compreender que um entendimento mais profundo de sua área de formação não é suficiente para dar conta de todo o processo de ensino. Ele precisa compreender e dominar as outras áreas e fazer relação entre elas.

O trabalho do professor com interdisciplinaridade só acontecerá de fato se ele for capaz de partilhar o domínio do saber, se tiver a coragem necessária para abandonar o conforto da linguagem estritamente técnica e aventurar-se num domínio que é de todos e de que, portanto, ninguém é proprietário exclusivo. A interdisciplinaridade está levando as pessoas a pensar e agir em diferentes sentidos, resgatando o caráter de interdependência e interatividade existente entre as coisas e as ideias.

Diante do contexto da realidade, percebe-se que a humanidade vive dentro de uma grande teia de interações, onde todos estão interligados de algum modo, visto que os indivíduos não usam apenas a razão para aprender, mas também a intuição, as emoções, sensações e sentimentos. Sendo assim, a 
interdisciplinaridade vem auxiliar os educadores no trabalho pedagógico, criando articulação entre o ensinar e o aprender.

Acredita-se que a proposta de ensino por projetos é uma forma prática de tratar os conteúdos de forma integrada, onde envolve a interdisciplinaridade. O projeto torna a aprendizagem mais dinâmica, eficiente e motivadora, o que se evidenciou nos resultados dos alunos da turma beneficiada pelas ações. As aulas se tornaram mais agradáveis, houve um maior interesse pela disciplina de Geografia, os alunos foram mais responsáveis com as tarefas em aula e em casa, e assimilaram melhor os conteúdos trabalhados.

Os resultados das avaliações aplicadas durante o primeiro trimestre de duas turmas de $6^{0}$ ano são mostrados nos gráficos abaixo:

O $6^{\circ}$ ano turma A (com atividades do projeto) e $6^{\circ}$ ano turma B (sem as atividades projeto).

Gráfico 1: Avaliações de Geografia 6ํㅡㄹ

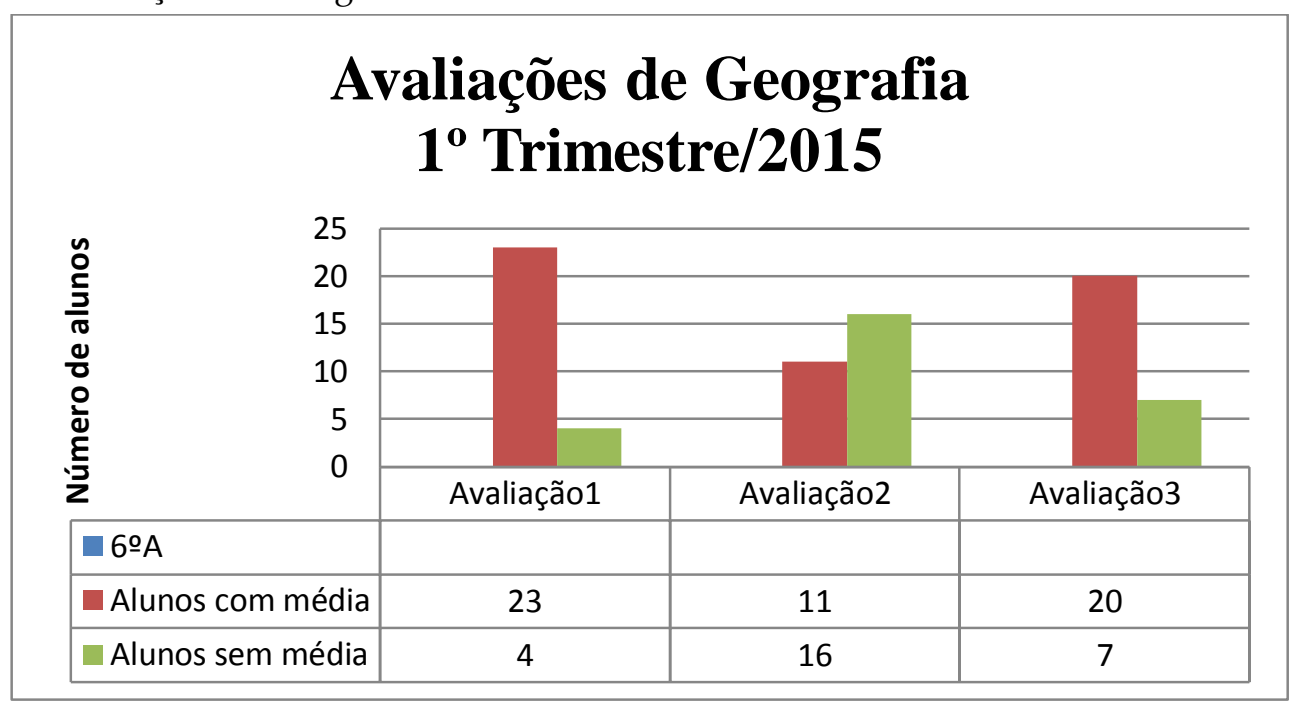

Fonte: Autores

Gráfico 2: Avaliações de Geografia 6ํㅡ B

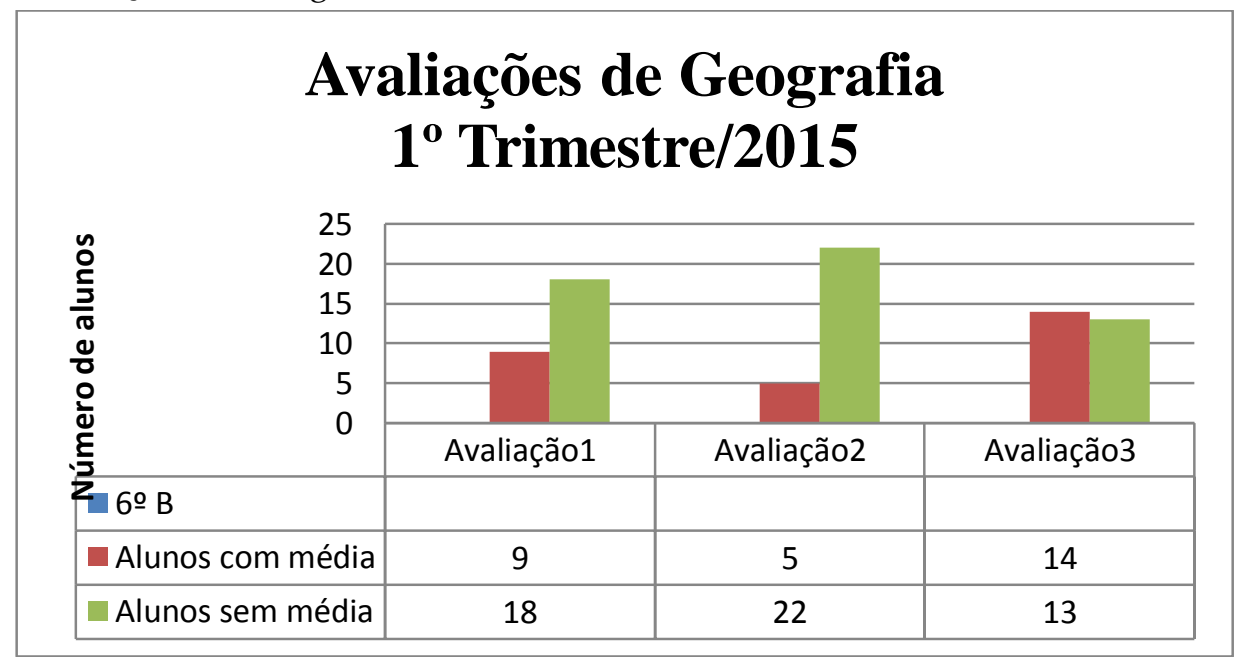

Fonte: Autores 
Gráfico 3: Média Final de Geografia 6ํㅜ A

\title{
Média Final de Geografia / $6^{\circ} \mathrm{A}$ $1^{0}$ Trimestre de 2015
}

\author{
Alunos com média $\quad$ Alunos sem média

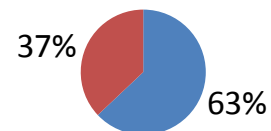

Fonte: Autores

Gráfico 3: Média Final de Geografia 6ํㅡ B

\section{Média Final de Geografia / $6^{\circ}$ B $1^{\circ}$ Trimestre de 2015}

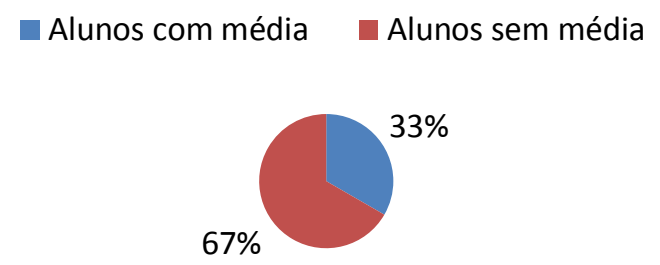

Fonte: Autores

A Educação Ambiental não foi avaliada como nota para o trimestre, mas ela contribuiu para a apropriação do conhecimento pelo aluno. As noções básicas de espaço e tempo (fundamentais para o aprendizado de Geografia), os conceitos de produção das necessidades e de transformação foram trabalhados a partir de eixos temáticos, já que a concepção de trabalho, sociedade e natureza estão interrelacionados, pois a sociedade, através do trabalho, se relaciona com a natureza.

Com isso, pode-se concluir que o trabalho realizado foi significativo e apresentou resultados positivos no processo de ensino-aprendizagem dos alunos, nos conteúdos referentes à disciplina de Geografia. Além disso, tendo os alunos os elementos necessários para identificar e relacionar as diversas maneiras de como a sociedade se apropria da natureza, através do seu trabalho e da cultura, modificam continuamente o espaço em que vive. E de posse desse conhecimento, terão condições de analisar até que ponto o meio ambiente está sendo agredido num contexto próximo, e dessa forma, com o domínio do conhecimento científico e do exercício da cidadania, poderá tomar decisões conscientemente para a mudança de comportamento. 
AULER, D. Enfoque ciência-tecnologia-sociedade: pressupostos para o contexto brasileiro. Ciência \& Ensino. v. 1, p. 1-20, 2007.

BRASIL. Parâmetros curriculares nacionais: Temas Transversais. Brasília: MEC/SEB, 1998b.

BRASIL. Parâmetros Curriculares Nacionais: meio ambiente e saúde/temas transversais. Secretaria de Educação Fundamental. Brasília: MEC/SEF, V.9, 1997.

FAZENDA, I. C. A. (Org.) Práticas interdisciplinares na escola. São Paulo: Cortez, 2011. p.65-78.

FAZENDA. Ivani. Integração e Interdisciplinaridade no Ensino Brasileiro: Efetividade ou ideologia? São Paulo: Loyola, 1992.

FAZENDA, Ivani et al. (Org.). Práticas Interdisciplinares na escola. 3. ed. São Paulo: Cortez, 1996.

FREITAS, K. S. Equipamentos e materiais didáticos. Brasília: Universidade de Brasília, 2007. Disponível em: <htpp://portal.mec.gov.br/seb/arquivos/pdf/profunc/equip_mat_dit .pdf $>$. Acesso em: 23/07/2015

GIL, Antônio Carlos. Como elaborar Projetos de Pesquisa. 3 ed. São Paulo: Atlas, 1991.

JAPIASSU, Hilton. Interdisciplinaridade e patologia do saber. Rio de Janeiro: Imago, 1976.

LEITE, L. H. A. Pedagogia de projetos: Intervenção no presente. Presença pedagógica. 1996. n.8. p. 2433.

MORIM, E. Os sete saberes necessários à educação do futuro. 5. ed. São Paulo: Cortez; Brasília, D.F.: UNESCO 2002.

NOGUEIRA, N. R. Pedagogia dos projetos: uma jornada interdisciplinar rumo ao desenvolvimento das múltiplas inteligências. São Paulo: Érica, 2001.

OLIVEIRA, M.A.F.C.; BUENO, S.M.V. Comunicação educativa do enfermeiro na promoção da saúde sexual escolar. Ver. Latino-Am. Enfermagem, Ribeirão Preto, v.5 m.3 p. 71,81, 1997. 